\title{
Does mesenchymal stem cell improve the liver regeneration after the $70 \%$ hepatectomy? ${ }^{1}$
}

\author{
Ana Karina Soares Alves', Valéria Lanzoni", Rogério Aoki Fuziy"', Rita Maria Aparecida Monteiro \\ Moura Franco"', Carlos Toshinori Maeda"', Gaspar de Jesus Lopes Filho'v , Marcelo Moura Linhares ${ }^{\vee}$
}

'Fellow Master degree, Postgraduate Program in Interdisciplinary Surgical Sciences, Universidade Federal de São Paulo (UNIFESP), Brazil. Conception and design of the study; acquisition, analysis and interpretation of data; final approval of the version to be published.

"PhD, Department of Pathology, UNIFESP, Sao Paulo-SP, Brazil. Acquisition, analysis and interpretation of data; final approval of the version to be published.

I'Associate Professor, Division of Surgical Gastroenterology, Department of Surgery, UNIFESP, Sao Paulo-SP, Brazil. Intellectual content of the study, final approval of the version to be published.

IVPhD, Chairman, Division of Surgical Gastroenterology, Department of Surgery, UNIFESP, Sao Paulo-SP, Brazil. Intellectual content of the study, final approval of the version to be published.

'PhD, Associate Professor, Division of Surgical Gastroenterology, Department of Surgery, UNIFESP, Sao Paulo-SP, Brazil. Conception and design of the study; acquisition, analysis and interpretation of data; drafting the article; final approval of the version to be published.

\begin{abstract}
Purpose: To evaluate the effects of mesenchymal stem cells on liver regeneration in rats following a $70 \%$ hepatectomy.

Methods: Forty rats were subjected to $70 \%$ hepatectomy and then $\sim 10^{6}$ mesenchymal stem cells (test group), or saline solution (control group), were infused into their livers via the portal vein. Each treatment group was divided into early and late subgroups (euthanized $3 \mathrm{~d}$ and $5 \mathrm{~d}$ following the operation, respectively). Group comparisons of Albumin, aminotransaminases (AST, ALT), and Alcaline Phosphatase (AP) levels, proliferative index (ki-67+ straining), and mitotic cell counts were conducted.

Results: No significant differences in liver regeneration rate, number of mitoses, proliferative index, or serum levels of albumin, AST, or AP were observed. ALT levels were higher in the test group than in the control group $(p<.05)$.

Conclusions: Mesenchymal stem-cell therapy did not improve liver regeneration rate $3 \mathrm{~d}$ or 5 $d$ after $70 \%$ hepatectomy in rats. Likewise, the therapy appeared not to affect liver function, proliferative index, or number of mitoses significantly.

Key words: Mesenchymal Stem Cell Transplantation. Liver Regeneration. Hepatectomy. Celland Tissue-Based Therapy. Rats.
\end{abstract}




\section{Introduction}

Advances in the development and refinement of surgical techniques, combined with improvements in multidisciplinary therapy for oncological diseases, have led to indications for increasingly complicated liver resections. However, the mortality rates for patients undergoing these surgeries remain around $5 \%$, even in referral centers. Posthepatectomy liver failure (PHLF) is the main cause of death for these patients, and mortality rates greater than $20 \%$ have been reported for PHLF patients with a history of chronic liver disease or cirrhosis ${ }^{1,2}$. A key risk factor that is associated with PHLF is small liver volume ${ }^{3}$. Therefore, portal vein embolization, portal vein ligation, two-stage hepatectomy, and ALPPS (Associating Liver Partition and Portal Ligation for Staged Hepatectomy) are a few of the strategies that have been developed to guarantee hypertrophy of the remaining liver tissue following surgery in order to prevent $\mathrm{PHLF}^{4,5}$.

More recently, the potential for cell therapy to provide molecular and/or cellular stimuli to replace lesioned or lost tissues has been investigated, with the goal of restoring liver function ${ }^{6}$. To explore the mechanisms involved, the transdifferentiation of mesenchymal stem cells into hepatocytes, cell fusion experiments with formation of a hybrid hepatocytic, and investigations of paracrine and immunomodulatory effects have been performed ${ }^{7,8}$. In particular, an infusion of mesenchymal stem cell lysate, rather than whole cells, was found to improve liver regeneration. This effect was also accompanied by an improved biochemical profile and a reduction in cell apoptosis. Taken together, these results support the hypothesis that paracrine factors can improve the function of lesioned tissue by reducing inflammation and increasing vasculogenesis ${ }^{9}$. Furthermore, in experimental rat models involving a $70 \%$ hepatectomy followed by a stem cell transplant via the portal or peripheral veins, significant improvements in the rate of liver regeneration were observed, and this was accompanied by improvements in the Ki-67 index, in the mitotic index, and in real-time reverse transcriptasepolymerase chain reaction (RT-PCR) compared to the control groups ${ }^{10-12}$.

While some studies have demonstrated that cell therapy can be beneficial following liver resection, a lack of standardization regarding the number of cells administered, the type of cell administered, and the grade of liver lesion treated have prevented a comparison and validation of cell therapy as a clinical application. Therefore, in this study, liver regeneration was evaluated in a rat model three days and five days after a $70 \%$ partial hepatectomy followed by a transplantation of mesenchymal stem cells through the portal vein.

\section{Methods}

The Ethics Committee of UNIFESP approved this study (CEP 0759/07) and both national and institutional protocols for the care and use of experimental animals were followed.

Forty male Wistar rats $(250-350$; $\mathrm{n}=40$ ) were obtained from the Center for the Development of Experimental Models (Sao Paulo, Brazil).

Briefly, the animals underwent a $70 \%$ hepatectomy with bloc ligation of the left and right regions of the median lobes and the left lateral lobe. This was followed by an infusion of $10^{6}$ mesenchymal stem cells (test group) or a PBS buffer solution (control group) through the portal vein. These two groups were then each subdivided into two groups to evaluate liver regeneration on the third day and on the fifth day following surgery, according with the 
scheme on the Figure 1. For these four groups, each total regenerated liver (TR) was resected and weighed.

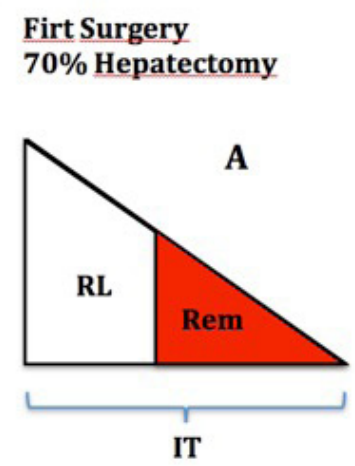

\section{Second Surgery \\ Eutanasia}

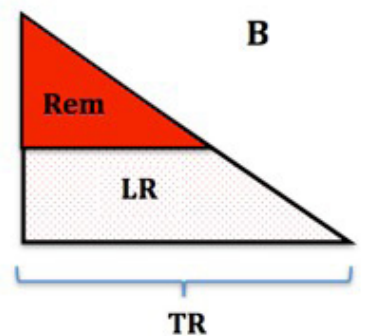

TR formula:

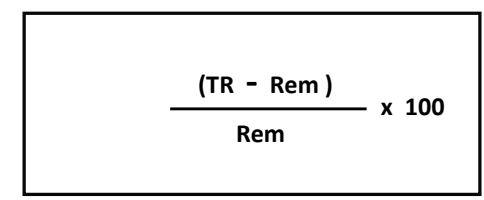

Rem $=I T \times 0.7$

$\mathrm{TR}=$ Rem + LR

$\mathrm{LRR}=$ liver regeneration rate

$\mathrm{TR}=$ total liver regenerated

Rem = liver remnant

IT = initial total liver

$\mathrm{LR}=$ liver regeneration

Analysis of the proliferative index and the number of mitoses events

Histological slices of liver tissue were stained with eosin and hematoxylin, and then the number of hepatocytes present during mitosis were calculated. The slices were also incubated with an anti-Ki-67 antibody to calculate the positive: total Ki-67 hepatocyte ratio.

\section{Biochemical analyses}

Blood samples were collected from the after anesthesia. After centrifugation, the resulting pellet was re-suspended in $4 \mathrm{~mL}$ of Dulbecco's modified eagle medium (DMEM) and the mononuclear cells were separated using a Histopaque protocol (Sigma-Aldrich, St. Louis, MO, USA). The mononuclear cells were re-suspended in low-glucose DMEM supplemented with $10 \%$ fetal bovine serum (FBS, Gibco/Invitrogen) and were distributed in $75 \mathrm{~cm}^{2}$ bottles ( $2 \times 10^{5}$ cells/bottle). The cells were maintained in a $5 \% \mathrm{CO}_{2}$ incubator at $37^{\circ} \mathrm{C}$ for 10 to $15 \mathrm{~d}$. The cultures were maintained until their sixth passage.

\section{Liver regeneration rate ( $L R R$ )}

The weight of the REMs were used to calculate the LRRs according to the following retro-orbital plexus during surgery and at the
time of euthanasia. Following the separation of plasma for each of the samples, a standard method to measure alanine transaminase $(A L T)$, alanine aminotransferase (AST), alkaline phosphatase (PA), and albumin levels was used.

\section{Statistical analysis}

The Statistical Package for Social Sciences (SPSS v 18.0, Chicago, IL, USA) was used to perform statistical analyses. LRRs and the percentages of variation (delta) for the study variables were calculated. Student's $t$-test was applied to the parametric variables (e.g., LRR, 
delta albumin), while the Mann-Whitney test was applied to the non-parametric variables (e.g., delta ALT, AST, PA, Ki-67, and the number of mitosis events). The significance level was set at 0.05 or $5 \%$.

\section{Results}

There was no significant variation between any of the parameters examined, except for the TGP level which was significantly higher in the test group than in the control group
(Tables 1 and 2). There were no differences between the test group and the control group regarding proliferative index values and the number of mitosis events (Tables 3 and 4). In addition, the LRRs for the control and test groups 3 and 5 days after surgery did not differ. For the former, the values for the test group and the control group were: $116.0 \pm 28.6(n=$ 7) and $126.0 \pm 24.1(n=9)$, respectively $(p=$ $0.490)$. For the latter, the values were: 159.8 $\pm 46.5(n=10)$ and $141.8 \pm 22.7(n=10)$, respectively $(p=0.406)$.

Table 1 - Comparison of the variations in the levels of AF, AST, ALT, and albumin detected between the test and control groups on the third post-operative day.

\begin{tabular}{|c|c|c|c|c|c|c|c|c|c|c|c|c|c|c|}
\hline \multirow{2}{*}{$\begin{array}{l}\text { Variation } \\
(\Delta) \\
\text { 3rd post- } \\
\text { op minus } \\
\text { pre-op }\end{array}$} & \multicolumn{6}{|c|}{ control } & \multicolumn{6}{|c|}{ test } & \multirow{2}{*}{$\mathbf{U}$} & \multirow{2}{*}{ p } \\
\hline & $\mathbf{N}$ & Mean & SD & Median & Min & Max & $\mathbf{N}$ & Mean & SD & Median & Min & Max & & \\
\hline AF & 7 & 92.4 & 66.2 & 82.7 & 21.9 & 200 & 9 & 44.8 & 36.9 & 39.9 & -6.5 & 100 & 18 & 0.153 \\
\hline AST & 6 & 20.6 & 24.6 & 22.3 & -13.5 & 51.5 & 8 & 75.0 & 77.8 & 49.1 & 19.2 & 257.7 & 9 & 0.053 \\
\hline ALT & 7 & 17.6 & 19.3 & 20 & 0 & 50 & 9 & 94.9 & 56.4 & 99.9 & 16.7 & 200.1 & 5 & $0.005^{*}$ \\
\hline Albumin & 7 & -19.5 & 6.0 & -21.3 & -29.2 & -12 & 9 & -17.9 & 10.3 & -12.8 & -38.9 & -6.4 & 23 & 0.368 \\
\hline
\end{tabular}

Table 2 - Comparison of the variations in the levels of AF, AST, ALT, and albumin detected between the test and control groups on the fifth post-operative day.

\begin{tabular}{|c|c|c|c|c|c|c|c|c|c|c|c|c|c|c|}
\hline \multirow{2}{*}{$\begin{array}{l}\text { Variation } \\
(\Delta) \\
5 \text { th } \\
\text { post-op } \\
\text { minus } \\
\text { pre-op }\end{array}$} & \multicolumn{6}{|c|}{ control } & \multicolumn{6}{|c|}{ test } & \multirow[b]{2}{*}{ U } & \multirow[b]{2}{*}{$\mathbf{p}$} \\
\hline & $\mathbf{N}$ & Mean & SD & Median & Min & Max & $\mathbf{N}$ & Mean & SD & Median & Min & Max & & \\
\hline AF & 10 & 44.9 & 32.4 & 43.0 & 13.5 & 120 & 10 & 35.80 & 24.8 & 36.6 & -6.7 & 76 & 44 & 0.650 \\
\hline AST & 10 & 48.8 & 54.5 & 40.6 & -29.1 & 173.1 & 10 & 31.0 & 32.3 & 27.9 & -12.9 & 81.5 & 40.5 & 0.473 \\
\hline ALT & 10 & 6.4 & 51.9 & 17.0 & -100 & 100 & 10 & 41.7 & 23.7 & 33.3 & 20 & 99.9 & 20 & $0.023 *$ \\
\hline Albumin & 10 & -19.5 & 8.7 & -20.6 & -30.2 & -3.8 & 10 & -16.9 & 7.05 & -18.1 & -28 & -3.6 & 39 & 0.406 \\
\hline
\end{tabular}


Table 3 - Evaluation of the proliferative index (Ki-67) and mitotic index for the test and control groups on the third post-operative day.

\begin{tabular}{|c|c|c|c|c|c|c|c|c|c|c|c|c|c|c|}
\hline \multirow{2}{*}{ Variables } & \multicolumn{6}{|c|}{ control } & \multicolumn{6}{|c|}{ test } & \multirow{2}{*}{$\mathbf{U}$} & \multirow{2}{*}{$\mathbf{p}$} \\
\hline & $\mathbf{N}$ & Mean & SD & Median & Min & Max & $\mathbf{N}$ & Mean & SD & Median & Min & Max & & \\
\hline Ki67 & 7 & 0.44 & 0.15 & 0.41 & 0.26 & 0.62 & 9 & 0.3 & 0.19 & 0.39 & 0.14 & 0.69 & 27 & 0.634 \\
\hline $\begin{array}{l}\text { Mitotic } \\
\text { Index }\end{array}$ & 7 & 6.29 & 4.42 & 5.00 & 2.00 & 14.00 & 9 & 5.11 & 2.09 & 5.00 & 3.00 & 10.00 & 30 & 0.872 \\
\hline
\end{tabular}

Table 4 - Evaluation of the proliferative index (Ki-67) and the mitotic index for the test and control groups on the fifth day following surgery and infusion.

\begin{tabular}{|c|c|c|c|c|c|c|c|c|c|c|c|c|c|c|}
\hline \multirow{2}{*}{ Variables } & \multicolumn{6}{|c|}{ control } & \multicolumn{6}{|c|}{ test } & \multirow{2}{*}{ U } & \multirow{2}{*}{$p$} \\
\hline & $\mathbf{N}$ & Mean & SD & Median & Min & Max & $\mathbf{N}$ & Mean & SD & Median & Min & Max & & \\
\hline Ki67 & 10 & 0.10 & 0.08 & 0.0983 & 0.02 & 0.28 & 10 & 0.16 & 0.08 & 0.1412 & 0.05 & 0.28 & 30 & 0.131 \\
\hline $\begin{array}{l}\text { Mitotic } \\
\text { Index }\end{array}$ & 10 & 1.00 & 0.67 & 1.00 & 0.00 & 2.00 & 10 & 0.60 & 0.52 & 1.00 & 0.00 & 1.00 & 34 & 0.165 \\
\hline
\end{tabular}

\section{Discussion}

For surgeries that include resection of a large portion of the liver, the residual volume of the liver is critical. Moreover, an increased risk of liver failure exists despite the high capacity for regeneration by this organ. This situation is even more acute for patients with a history of cirrhosis or chemotherapy ${ }^{13}$. A literature review with respect to chronic liver lesions identified eleven clinical trials that have investigated the effect of mesenchymal cells on the treatment of hepatic cirrhosis. However, the models of liver disease were quite different, and thus, a wide variation in the methodology and in the types of mesenchymal cells used was observed. Furthermore, none of these trials yielded strong scientific evidence ${ }^{14}$. Consequently, the benefits of liver resection remain to be confirmed, particularly regarding the therapeutic potential of a mesenchymal cell infusion for hepatic lesions. Improvements in liver tissue regeneration, either through transdifferentiation, cell fusion, release of trophic factors, or immunomodulation, also remain to be determined.
In the present study, it was examined whether an infusion of $10^{6}$ stem cells following a $70 \%$ hepatectomy could lead to an increase in liver regeneration. When LRRs were compared for the test and control groups three and five days after each surgery and infusion were performed, no differences were detected. In addition, the rate of cell proliferation, the mitotic index values, and biochemical analyses showed no differences between the rats that received cell therapy and the control rats. In a literature search, only three studies were found to use mesenchymal stem cells in a similar hepactectomy model. In the model reported by Kanazawa et al. ${ }^{15}$ involving an ischemia method, the same administration route and cells that were used in the present method were applied, and an increase in the LRR was observed for the group that received the mesenchymal cell therapy. In the two other studies, both of the same authors, $3 \times 10^{7}$ and $2 \times 10^{7}$ cells were transfused, respectively, and higher LRRs were also observed compared to the control groups ${ }^{10,11}$. However, in a report by Yu et al. ${ }^{16}$ when $5 \times 10^{6}$ mesenchymal stem cells were applied to an $85 \%$ hepatectomy 
model, a higher LRR was not achieved in the mesenchymal cell group, but only in the group preconditioned with hypoxia.

The biochemical analyses performed in these studies yielded distinct and conflicting results. Furthermore, only one study previously calculated the proliferative index and the mitotic index to estimate improvements in liver regeneration ${ }^{11}$.

Various factors may account for the differences in results between the present study and previous studies that evaluated liver regeneration. Initially, differences in the number of cells used are obvious. It would seem logical that the number of cells applied could be directly proportional to the magnitude of the observed effect. However, variations in the methods used to culture the cells in vitro, and the lack of specific surface markers to confirm each population of mesenchymal cells, makes it difficult to directly compare the studies.

Based on the conflicting results that have been reported, and the small number of comparable studies available, it is difficult to determine whether the present results confirm or negate a possible effect of mesenchymal stem cells on the rat model of acute liver lesion that was investigated. Moreover, there are various aspects that might serve as confounding factors in this evaluation. For example, there is the belief that the role played by mesenchymal cells can be measured in an animal model in which regeneration occurs with a low index of hepatic failure. Indeed, the normal mechanisms by which liver regeneration occurs could be enough itself to repair the liver lesion without the action of transplanted mesenchymal cells, thereby requiring that a stimuli of greater magnitude is needed, such as a $90 \%$ hepatectomy. Another point worthy of discussion is the imprecise nature of calculating liver regeneration. In the previous and in the present study, this calculation was based on an estimate of liver remnant weight based on the initial weight of the resected liver. Consequently, a wide variation in the percentage of mass resected was observed, and this may have led to a possibly bias in our results. Furthermore, the mesenchymal stem cell culture used represents a heterogeneous pool of cells, and the number of cells infused may or may not be responsible for the results observed. Correspondingly, the present results may be a characteristic of the infused cells and/ or the particles released by them.

Cell therapy may have the potential to accelerate and/or stimulate tissue repair processes. Furthermore, mesenchymal cells represent a cell source that could provide sufficient numbers of cells to administer a graft treatment for patients that have undergone extensive liver resection to remove a lesion. However, certain issues need to be resolved before this therapy can be adopted into clinical practice. First, it needs to be demonstrated whether this therapy provides a real benefit. Then, the most effective cell clone needs to be identified, as well as the dose of cells to be infused, the number of infusions required, and the best means to achieve a successful cell transplant. Furthermore, a characterization of paracrine and immunomodulatory factors is needed to evaluate the viability of an allogeneic transplant. To pursue these goals, additional research is needed that involves larger sample sizes and validation of the model in other animals. However, the present findings support the pursuit of these additional investigations.

\section{Conclusions}

Mesenchymal stem-cell therapy did not improve liver regeneration rate $3 d$ or $5 d$ after $70 \%$ hepatectomy in rats. Likewise, the therapy appeared not to affect liver function, proliferative index, or number of mitoses significantly. 


\section{References}

1. Simmonds PC, Primrose JN, Colquitt JL, Garden OJ, Poston GJ, Rees M. Surgical resection of hepatic metastases from colorectal cancer: a systematic review of published studies. $\mathrm{Br} J$ Cancer. 2006 Apr 10;94(7):982-99. doi: 10.1038/ sj.bjc.6603033.

2. Guglielmi A, Ruzzenente A, Conci S, Valdegamberi A, lacono $C$. How much remnant isenough in liver resection? Dig Surg. 2012;29(1):6-17. doi: 10.1159/000335713.

3. Narita $M$, Oussoultzoglou E, Bachellier P, Jaeck D, Uemoto S. Post-hepatectomy liver failure in patients with colorectal liver metastases. Surg Today. 2015 Oct;45(10):1218-26. doi: 10.1007/s00595015-1113-7.

4. Schadde E, Malagó M, HernandezAlejandro R, Li J, Abdalla E, Ardiles V, Lurje G, Vyas S, Machado MA, de Santibañes E. Monosegment ALPPS hepatectomy: extending resectability by rapid hypertrophy. Surgery. 2015 Apr;157(4):676-89. doi: 10.1016/j.surg.2014.11.015.

5. Jorge $O$, Torres $M$, Assun $M$, Lima $C$, et al. Associating liver partition and portal vein ligation. $A B C D$ Arq. Bras. Cir. Dig. 2012;25(4):290-2.

6. Dalgetty DM, Medine CN, Iredale JP, Hay DC. Progress and future challenges in stem cell-derived liver technologies. Am J Physiol Gastrointest Liver Physiol. 2009 Aug;297(2):G241-8. doi: 10.1152/ ajpgi.00138.2009.

7. Stutchfield BM, Rashid S, Forbes SJ, Wigmore SJ. Practical barriers to delivering autologous bone marrow stem cell therapy as an adjunct to liver resection. Stem Cells Dev. 2010 Feb;19(2):155-62. doi: 10.1089/ scd.2009.0412.

8. Zhou P, Wirthlin L, McGee J, Annett G, Nolta J. Contribution of human hematopoietic stem cells to liver repair. Semin Immunopathol. 2009 Sep;31(3):411-9. doi: 10.1007/s00281009-0166-3.

9. Herencia C, Almadén $Y$, Martínez-Moreno JM, Espejo I, Herrera C, Pérez-Sánchez C, Guerrero F, Ciria R, Briceño FJ, Ferrín G, de la Mata M, Muñoz-Castañeda JR. Human mesenchymal stromal cell lysates as a novel strategy to recover liver function. Regen Med. 2015;10(1):25-38. doi: 10.2217/ rme.14.59.

10. Kaibori $M$, Adachi $Y$, Shimo T, Ishizaki M, Matsui K, Tanaka Y, Ohishi M, Araki Y, Tokuhara K, Okumura T, Nishizawa M, Kwon $\mathrm{AH}$. Bone marrow cells enhance liver regeneration after massive hepatectomy in mice. Dig Dis Sci. 2014 Jul;59(7):1484-9. doi: 10.1007/s10620-014-3032-7.

11.Kaibori M, Adachi Y, Shimo T, Ishizaki M, MatsuiK, Tanaka Y, Ohishi M, ArakiY, Okumura T, Nishizawa $M$, Kwon AH. Stimulation of liver regeneration after hepatectomy in mice by injection of bone marrow mesenchymal stem cells via the portal vein. Transplant Proc. 2012 May;44(4):1107-9. doi: 10.1016/j.transproceed.2012.01.088.

12.Seki T, Yokoyama Y, Nagasaki H, Kokuryo $T$, Nagino $M$. Adipose tissue-derived mesenchymal stem cell transplantation promotes hepatic regeneration after hepatic ischemia-reperfusion and subsequent hepatectomy in rats. J Surg Res. 2012 Nov;178(1):63-70. doi: 10.1016/j. jss.2012.02.014.

13.Kaibori M, Ha-Kawa SK, Ishizaki M, Matsui K, Saito T, Kwon AH, Kamiyama Y. HA/GSA-Rmax ratio as a predictor of postoperative liver failure. World J Surg. 2008 Nov;32(11):24108. doi: 10.1007/s00268-008-9725-3.

14.am Esch JS 2nd, Knoefel WT, Klein $M$, Ghodsizad A, Fuerst G, Poll LW, Piechaczek C, Burchardt ER, Feifel N, Stoldt V, Stockschläder M, Stoecklein N, Tustas RY, Eisenberger CF, Peiper M, Häussinger D, Hosch SB. Portal application of autologous CD133+ bone marrow cells to the liver: a novel concept to support hepatic regeneration. Stem Cells. 2005 Apr;23(4):463-70. doi: 10.1634/ stemcells.2004-0283.

15.Irfan A, Ahmed I. Could stem cell therapy be the cure in liver cirrhosis? J Clin Exp Hepatol. 2015 Jun;5(2):142-6. doi: 10.1016/j. jceh.2014.03.042.

16. Kanazawa $\mathrm{H}$, Fujimoto $\mathrm{Y}$, Teratani T, Iwasaki J, Kasahara N, Negishi K, Tsuruyama T, Uemoto S, Kobayashi E. Bone marrowderived mesenchymal stem cells ameliorate hepatic ischemia reperfusion injury in a rat model. PLoS One. 2011 Apr 29;6(4):e19195. doi: 10.1371/journal.pone.0019195. 
17.Yu J, Yin S, Zhang W, Gao F, Liu Y, Chen Z, Zhang $M$, He J, Zheng S. Hypoxia preconditioned bone marrow mesenchymal stem cells promote liver regeneration in a rat massive hepatectomy model. Stem Cell Res Ther. 2013 Jul 15;4(4):83. doi: 10.1186/ scrt234.

\section{Correspondence:}

Marcelo Moura Linhares

Rua Leandro Dupre, 334

04025-002 São Paulo - SP Brasil

Tel.: (55 11)5531-3621/98126-1188

mlinhares@unifesp.br

Received: Mar 02, 2017

Review: May 08, 2017

Accepted: June 05, 2017
Conflict of interest: none

Financial source: none

\begin{abstract}
${ }^{1}$ Research performed at Division of Surgical Gastroenterology, Department of Surgery, Universidade Federal de São Paulo (UNIFESP), Brazil. Part of Master degree thesis, Postgraduate Program in Interdisciplinary Surgical Sciences, UNIFESP. Tutor: Marcelo Moura Linhares.
\end{abstract}

